\title{
Behavioral Effects Mediated by the Modulatory Glycine Site of the NMDA Receptor in the Anterodorsal Striatum and Nucleus Accumbens
}

\author{
Beate D. Kretschmer and Werner J. Schmidt \\ Department of Neuropharmacology, University of Tübingen, 72074 Tübingen, Germany
}

The striatum and the nucleus accumbens are the main input structures of the basal ganglia (BG). They contribute differently to motor behavior controlled by the $B G$ in rats, e.g., stereotyped behavior, catalepsy, and locomotion. Whereas the striatum is predominantly involved in the control of sniffing behavior and catalepsy, the nucleus accumbens contributes to control of locomotion. To test whether the allosteric glycine site of the NMDA receptor complex modulates these behavioral variables, we injected the glycine-site antagonist 7-chlorokynurenate and the glycine-site agonist D-serine into the anterodorsal striatum and the nucleus accumbens and studied their influence on stereotypical snout contacts and locomotion. Additionally, the effects of intrastriatal injections of 7-chlorokynurenate on haloperidol- and $\mathrm{SCH} 23390$-induced catalepsy were investi- gated. 7-Chlorokynurenate enhanced stereotypical snout contacts in the anterodorsal striatum and in the nucleus accumbens but did not change spontaneous locomotion in either of these structures. Haloperidol- but not SCH 23390-induced catalepsy was attenuated by intrastriatally administered 7-chlorokynurenate. The glycine-site agonist D-serine had no effect on stereotypical snout contacts and locomotion. The results suggest that motor behavior mediated by the striatopallidal output pathway is modulated by the glycine site, whereas motor behavior mediated by the accumbopallidal and striatonigral output pathway is not.

Key words: stereotypy; locomotion; striatum; nucleus accumbens; NMDA; glycine; 7-chlorokynurenate; D-serine
Motor behavior is initiated, modulated, and controlled by parallel and functionally distinct loops coming from the cortex, passing the basal ganglia (BG), and reentering the cortex (Alexander et al., 1986; Alexander and Crutcher, 1990). The striatum and the nucleus accumbens are the main input structures of the sensorimotor- and limbicmotor-related loops, respectively. The structures receive glutamatergic input from the cortex and dopaminergic input from the midbrain. The dopamine-glutamate balance in the striatum and the nucleus accumbens contributes to motor behavior in the following ways.

In the anterodorsal striatum, local stimulation of the dopaminergic system (Staton and Solomon, 1984; Swerdlow and Koob, 1987), inhibition of the glutamatergic system via blockade of NMDA receptors, and disruption of the corticostriatal efferents mainly stimulate stereotyped behavior, such as sniffing and repetitive head movement (Scatton et al., 1982; Schmidt, 1986; Imperato et al., 1990; Pierce and Rebec, 1993). This behavior is enhanced by disruption of the corticostriatal efferents (Iversen et al., 1971). In contrast, blockade of the dopaminergic system induces catalepsy with rigidity and akinesia (Ellenbroek et al., 1985; Ossowska et al., 1990; Yoshida et al., 1994). These symptoms are antagonized by locally applied NMDA receptor antagonists, ablation of the frontal cortex, or quinolinic acid lesion of the striatum (Calderon et al., 1988; Yoshida et al., 1991; Hauber and

\footnotetext{
Received Aug. 30, 1995; revised Nov. 27, 1995; accepted Dec. 6, 1995.

This study was supported by the SFB 307 and the "Graduiertenkolleg Neurobiologie" of the Deutsche Forschungsgemeinschaft. We thank S. De Belle for critically reading this manuscript. The excellent technical assistance of Eva Wacker also is gratefully acknowledged.

Correspondence should be addressed to Beate D. Kretschmer, Department of Neuropharmacology, University of Tübingen, Mohlstrasse 54/1, 72074 Tübingen, Germany.

Copyright (C) 1996 Society for Neuroscience $\quad 0270-6474 / 96 / 161561-09 \$ 05.00 / 0$
}

Schmidt, 1993). However, local stimulation of the NMDA receptor reduces behavioral activity (Schmidt and Bury, 1988; Klockgether and Turski, 1993) and restores catalepsy in decorticated rats pretreated with a dopamine receptor antagonist (Yoshida et al., 1991).

In the nucleus accumbens, activation of the dopaminergic system, inhibition of the glutamatergic system, and neurotoxic lesion mainly stimulate locomotion (Donzanti and Uretsky, 1984; Staton and Solomon, 1984; Raffa et al., 1989; Imperato et al., 1990; Kelley and Throne, 1992; Weissenborn and Winn, 1992). Blockade of dopamine receptors by antagonists reduces locomotor behavior (Meyer, 1993), whereas activation of NMDA receptors induces controversial results: sedation, locomotion, or no effects (Donzanti and Uretsky, 1984; Imperato et al., 1990). Thus, it seems that the dopamine-glutamate balance in the striatum is involved mainly in the control of sniffing behavior, repetitive head movement, and catalepsy, whereas the balance in the nucleus accumbens is involved mainly in the control of locomotion. However, this "anatomofunctional" dichotomy has been discussed controversially in the past (LeMoal and Simon, 1991).

The glutamatergic system is positively modulated by a glycine site, which is located in the NMDA receptor complex next to the competitive, noncompetitive, and other binding sites (Wroblewski and Danysz, 1989). Recent studies showed that blockade of the glycine site enhances stereotyped behavior, has no effect on locomotion, and reduces catalepsy in dopamine D2 receptor antagonist-pretreated rats or monoamine-depleted rats when it is injected into the third ventricle (Koek and Colpaert, 1990; Kretschmer et al., 1994, 1995). However, systemically or intraventricularly given glycine-site antagonists are unable to attenuate dopamine D1 receptor antagonist-induced catalepsy (Kretschmer, 1994; Kretschmer et al., 1994). A glycine-site agonist, D-cycloserine, 
potentiates motor behavior mediated by a noncompetitive NMDA receptor antagonist and antagonizes motor behavior mediated by a competitive NMDA receptor antagonist, but has no effect on motor behavior by itself when it is systemically given (Kretschmer et al., 1992).

The purpose of this study was to elucidate the role of the glycine site in the striatum and the nucleus accumbens. To this end, the glycine-site antagonist 7-chlorokynurenate and the glycine-site agonist $\mathrm{D}$-serine were injected into the striatum and the nucleus accumbens, and the behavioral effects were measured. The effects were compared with single doses of the competitive NMDA receptor antagonist AP-5 and the NMDA receptor agonist NMDA.

\section{MATERIALS AND METHODS}

\section{Subjects}

Male Sprague-Dawley rats (Interfauna, Tuttlingen, Germany) weighing $240-260 \mathrm{gm}$ at the beginning of experiments were housed in groups of $7-10$ per cage $\left(70 \times 42 \times 30 \mathrm{~cm}^{3}\right)$ at a temperature of $22 \pm 3^{\circ} \mathrm{C}$ on a 12 hr light/dark cycle (light on: 6 A.M.). They were fed with standard laboratory chow (Atromin, Lage, Germany) $12 \mathrm{gm} / \mathrm{d}$ per rat after the experiments. Water was provided ad libitum.

\section{Surgery}

The rats were anesthetized with $350 \mathrm{mg} / \mathrm{kg}$ choralhydrate intraperitoneally. A local anesthetic (xyloneural forte 2\%; Stroschein Pharma, Hamburg, Germany) was given before opening the scalp. Atropine sulfate ( 0.8 $\mathrm{mg} / \mathrm{kg}$ ) was given pre- and postoperatively. Stainless steel cannulae (outer diameter $0.8 \mathrm{~mm}$ ) were lowered into the anterodorsal striatum according to the atlas of Paxinos and Watson (1986) (anterior-posterior $1.7 \mathrm{~mm}$ from bregma, lateral $\pm 2.5 \mathrm{~mm}$, ventral $3.4 \mathrm{~mm}$ from the dura) with a cannulae length of $15 \mathrm{~mm}$. In a second experiment, cannulae were lowered into the nucleus accumbens according to the atlas of Pellegrino et al. (1986) (anterior-posterior $3.4 \mathrm{~mm}$ from bregma, lateral \pm 1.5 , ventral $-6.5 \mathrm{~mm}$ from the dura) with a cannulae length of $18 \mathrm{~mm}$. Cannulae were fixed with stainless steel screws and dental cement. Rats were allowed to recover for $3-4 \mathrm{~d}$.

\section{Microinjection}

Injections were performed with stainless steel injection needles (outer diameter $0.45 \mathrm{~mm}$ ) connected with a polyethylene tube to a Hamilton syringe (Darmstadt, Gcrmany). The injection needles were lowered until they reached the injection site (striatum: ventral $-5.0 \mathrm{~mm}$ from skull; nucleus accumbens: ventral $-7.2 \mathrm{~mm}$ from skull). The injection volume $(0.5$ or $0.6 \mu \mathrm{l} / \mathrm{side})$ was administered by hand within $15 \mathrm{sec}$. The needle was left in place for an additional $30 \mathrm{sec}$ to allow diffusion.

\section{Drugs}

7-Chlorokynurenate (Research Biochemicals, Cologne, Germany), AP-5, and NMDA (Sigma, Diesenhofen, Germany) were dissolved with a minimum of $1 \mathrm{~N} \mathrm{NaOH}$, diluted to the final concentration with phosphate buffer $(0.2 \mathrm{M})$ and adjusted to $\mathrm{pH}$ 7.4. D-Serine (Fluka, Neu-Ulm, Germany) was dissolved in saline and adjusted to $\mathrm{pH}$ 7.4. Haloperidol (Janssen, Neuss, Germany) was diluted with saline. SCH 23390 (Research Biochemicals) was dissolved in saline. Control animals were treated with phosphate buffer, which served as vehicle substance.

7-Chlorokynurenate $(0.5 \mu \mathrm{l} / \mathrm{side})$ was injected $90 \mathrm{sec}$ before testing into the striatum and $5 \mathrm{~min}$ before testing into the nucleus accumbens. For comparability, one dose of 7-chlorokynurenate was additionally given 90 sec before testing in the nucleus accumbens. AP-5 $(0.5 \mu \mathrm{l} / \mathrm{side})$ was injected $5 \mathrm{~min}$ before testing, and NMDA $(0.5 \mu \mathrm{l} /$ side $)$ and D-serine $(0.6$ $\mu \mathrm{l} /$ side) were administered $90 \mathrm{sec}$ before testing into both structures. Haloperidol and SCH 23390 were intraperitoneally injected in a concentration of $1 \mathrm{ml} / \mathrm{kg} 30 \mathrm{~min}$ before the experiments.

\section{Behavioral procedure}

Sniffing behavior was quantified in an acrylic box called the "sniffing box" $\left(30 \times 10 \times 10 \mathrm{~cm}^{3}\right)$. The behavior was recorded on videotape for $5 \mathrm{~min}$ Afterward, the number of snout contacts was counted by typing the behavior successively into a computer. Snout contacts were defined as each contact of the rat's snout with the surrounding surface. If they contacted one place repeatedly, a withdrawal of the snout of $>0.5 \mathrm{~cm}$ was counted as a new contact (Schmidt, 1986).

Catalepsy was quantified in three tests in the following order of succession: (1) placing both forepaws of the rat on a horizontal bar $9 \mathrm{~cm}$ above the floor; (2) placing one forepaw of the rat on a podium $(3 \mathrm{~cm}$ high); and (3) hanging the rat with all paws on a vertical grid.

The time until active movement of one paw (desecnt latency) was measured with a maximum score of $180 \mathrm{sec}$.

Locomotor activity was quantified in an open field $\left(69 \times 69 \mathrm{~cm}^{2}\right)$, which was divided by lines into $4 \times 4$ squares ( $17.25 \mathrm{~cm}$ length of side) and illuminated with four red $25 \mathrm{~W}$ bulbs. Locomotor activity was recorded for $5 \mathrm{~min}$ on videotape followed by manually counting the number of line crossings.

\section{Experimental procedure}

On each experimental day, the rats were divided into two groups, one receiving the vehicle and the other receiving the drug. The treatment was changed each experimental day. A maximum of six injections (3 vehicle, 3 drug) were made with at least 48 hr between each injection. A 1 week delay was given to the rats between the first and the second sniffing box, open field, and catalepsy experiment. Each dose of 7-chlorokynurenate or D-serine had its own vehicle group.

Experiment 1: injection of drugs into the anterodorsal striatum. The effects of different doses of 7-chlorokynurenate $(2.5,5$, and $10 \mathrm{nmol})$ and D-serine $(1$ and $1.5 \mu \mathrm{mol}$ ) were quantified in the sniffing box and open field after injection into the anterodorsal striatum. The effects of $50 \mathrm{nmol}$ of AP-5 and $6.8 \mathrm{nmol}$ of NMDA also were tested in the sniffing box. Additionally, the effects of 5, 10, and $20 \mathrm{nmol}$ of 7-chlorokynurenate on haloperidol $(0.5 \mathrm{mg} / \mathrm{kg}$, i.p.)- and 10 and $20 \mathrm{nmol}$ of 7-chlorokynurenate on SCH $23390(0.5 \mathrm{mg} / \mathrm{kg}$, i.p. $)$-pretreated rats were investigated in the catalepsy test.

Experiment 2: injection of drugs into the nucleus accumbens. The effects of three doses of 7-chlorokynurenate $(2.5,5$, and $10 \mathrm{nmol})$ and two doses of $\mathrm{D}$-serine ( 1 and $1.5 \mu \mathrm{mol}$ ) injected into the nucleus accumbens were tested in the sniffing box and open field paradigms. The effects of $50 \mathrm{nmol}$ of AP-5 and $6.8 \mathrm{nmol}$ of NMDA on locomotor behavior were similarly tested.

\section{Histology}

After the experiments, the animals were killed by an overdose of pentobarbital. Brains were removed and sectioned into frontal $30 \mu \mathrm{m}$ slices and stained with cresyl violet for validation of the location of injection sites.

\section{Presentation and statistical analysis}

Because the individual activity baseline of snout contacts varied over time, these results are presented as differences from control means \pm SEM for clarity. In addition, the means of raw data \pm SEM are given in the legends of respective figures.

Raw data were used for all statistical evaluations, and they were submitted to the GBstat statistic package (Dynamic Microsystems, Silver Spring, MD). The data of the glycine-site ligands (7-chlorokynurenate and D-serine) from sniffing box and open field were analyzed using one-way ANOVA and post hoc Tukey's $t$ test where appropriate. The results of the single dose of 7-chlorokynurenate given $90 \mathrm{sec}$ before testing and the effects of the NMDA receptor ligands were analyzed by Student's $t$ test. Data of the catalepsy test were subjected to a KruskalWallis test followed by a Mann-Whitney $U$ test because they are not normal-distributed. A probability level of $\leq 0.05$ was accepted as a significant difference.

\section{RESULTS}

\section{Histology}

Figures 1 and 2 display the anterior-posterior, dorsal-ventral, and the lateral extent of the injection sites in the anterodorsal striatum and the nucleus accumbens. Data obtained from five rats with an injection site outside a $0.6 \mathrm{~mm}$ range of the aimed site were omitted from statistical analysis. Minimal tissue damage could been seen in each brain below the guide cannula. However, the damage was restricted to the area of the injection needle, and the volume of damage was similar in all brains. 


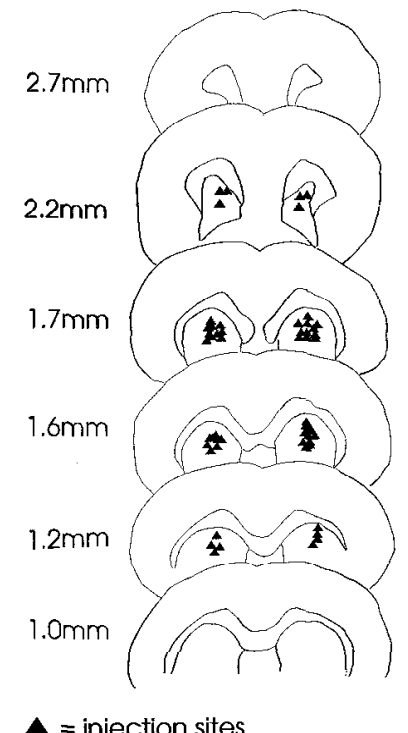

Figure 1. Transwerse section of the rat brain illustrated the position of the injection sites within the striatum according to the atlas of Paximus and Watson (1986). The visualization was performed by cresyl violet staining. Injection coordinates were: anterior-posterior $1.7 \mathrm{~mm}$ according to bregma, lateral $\pm 2.5 \mathrm{~mm}$, ventral $-5.0 \mathrm{~mm}$.

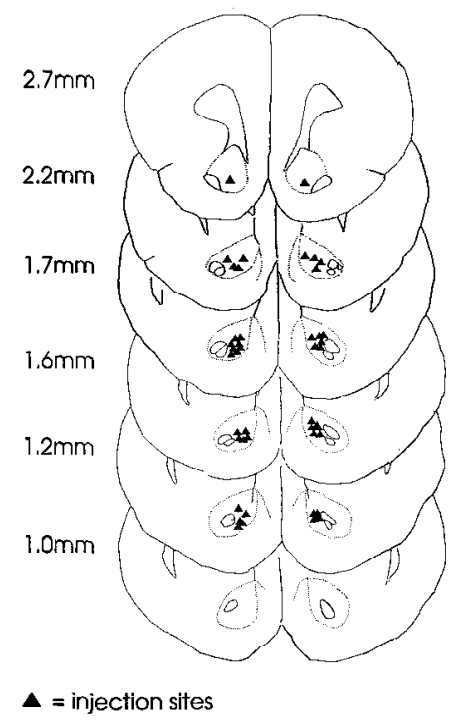

Figure 2. Transverse section of the rat brain illustrated the position of the injection sites within the nucleus accumbens according to the atlas of Paxinos and Watson (1986). The visualization was performed by cresylviolet staining. Injection coordinates were: anterior-posterior $3.4 \mathrm{~mm}$ according to bregma, lateral $\pm 1.5 \mathrm{~mm}$, ventral $-7.2 \mathrm{~mm}$ (Pellegrino et al., 1986).

\section{Experiment 1: injection of drugs into the anterodorsal striatum}

Effects of 7-chlorokynurenate and AP-5 after injection into the anterodorsul striaturn in sniffing box und/or open field. 7-Chlorokynurenate injected into the anterodorsal striatum enhanced in a dose-dependent manner the number of snout contacts in the sniffing box (Fig. $3 A)\left(F_{(5,65)}=6.2662 ; p<0.0001\right)$. Also, AP-5 increased the number of snout contacts when it was injected into the anterodorsal striatum (Fig. $3 B)(t=2.8322 ; p=0.0094)$. The number of line crossings was not enhanced by 7-chlorokynurenate (Fig. 4) $\left(F_{(5,65)}=2.5775 ; p=0.0354\right.$, relevant groups not significant in post hoc test).
Effects of 7-chlorokynurenate on haloperidol- or SCH 23390pretreated rats in the catalepsy test after injection into the anterodorsal striatum. Intrastriatally given 7-chlorokynurenate reduced the catalepsy induced by haloperidol pretreatment at all three doses $(5,10$, and $20 \mathrm{nmol})$ at the horizontal bar $\left(K W_{(3,57)}=14.488 ; p=\right.$ $0.0023)$. At the podium, only the highest dose (20 nmol) of 7 -chlorokynurenate was effective $\left(K W_{(3,57)}=7.819 ; p=0.0499\right)$. At the vertical grid, only $10 \mathrm{nmol}$ of 7 -chlorokynurenate reduced the descent latency in haloperidol-pretreated rats (Fig. 5) $\left(K W_{(3,57)}=12.561, p=0.0057\right)$. However, the anticataleptic effects of 7-chlorokynurenate were very short-lasting (5-15 $\mathrm{min}$ ). 7-Chlorokynurenate (10 and $20 \mathrm{nmol}$ ) had no effect on $\mathrm{SCH}$ 23390-pretreated rats in all three catalepsy tests (Fig. 6) (bar: $K W_{(2,31)}=1.866, p=0.3933$; podium: $K W_{(2,31)}=3.358, p=$ 0.1865 ; grid: $K W_{(2,31)}=7.312, p=0.0258$, relcvant groups not significant in post hoc test).

Effects of D-serine and NMDA after injection into the anterodorsal striatum in sniffing box and/or open field. Intrastriatally given D-serine (1 and $1.5 \mu \mathrm{mol}$ ) had no influence on the number of snout contacts measured in the sniffing box $\left(F_{(3,45)}=4.8099 ; p=\right.$ 0.0057 , relevant groups not significant in post hoc test) or on line crossings measured in the open field $\left(F_{(3,49)}=0.7438 ; p=\right.$ $0.5315)$, respectively. In contrast, $6.8 \mathrm{nmol}$ of NMDA reduced the number of snout contacts in the sniffing box $(t=2.428 ; p=$ 0.0247 ) when it was given into the anterodorsal striatum (Table 1). We did not observe convulsions in any of the rats.

\section{Experiment 2: injection of drugs into the nucleus accumbens}

Effects of 7-chlorokynurenute and AP-5 after injection into the nucleus accumbens in sniffing box andlor open field. 7-Chlorokynurenate increased the number of snout contacts in the sniffing box when it was injected into the nucleus accumbens (Fig. 7) $\left(F_{(5.70)}=9.0443 ; p<0.0001\right)$. However, intra-accumbal injection of 7-chlorokynurenate did not enhance the number of line crossings $\left(F_{(5,59)}=2.225 ; p=0.0648\right)$ as it was observed with AP-5 (Fig. $8 A, B)(t=2.423, p=0.0307)$. Injection of 7-chlorokynurenate $90 \mathrm{sec}$ before testing did not modulate the number of snout contacts $(t-1.9, p=0.0732)$ and line crossings $(t=1.7, p=0.1071)$ (Table 2).

Effects of D-serine and NMDA after injection into the nucleus accumbens in sniffing box and/or open field. The intra-accumbal injection of $\mathrm{D}$-serine did not influence the number of snout contacts in the sniffing box $\left(F_{(3,33)}=1.722 ; p=0.1836\right)$ or the number of line crossings in the open field $\left(F_{(3,52)}=2.5455 ; p=0.0667\right)$. NMDA also had no effect on the number of line crossings in the open field ( $t=0.04871 ; p=0.9614$ ) (Table 3 ), but it enhanced the time of inactivity (data not shown). No convulsions were observed in D-serine- or NMDA-treated rats.

\section{DISCUSSION}

The present study shows that stereotypical snout contacts, but not spontaneous locomotor behavior, are modulated by a glycine-site antagonist, whereas an NMDA receptor antagonist modulates both behavioral parameters. Furthermore, blockade of the glycine site can reduce catalepsy in rats pretreated with a dopamine D2 receptor antagonist, but not in rats pretreated with a dopamine D1 receptor antagonist. Stimulation of the glycine site has no effect on motor behavior, whereas NMDA itself reduces snout contacts in the striatum.

In the past, the effects of NMDA receptor agonists were controversially discussed. Although some groups found that NMDA reduces motor behavior when given into the striatum or nucleus 


\section{STRIATUM}
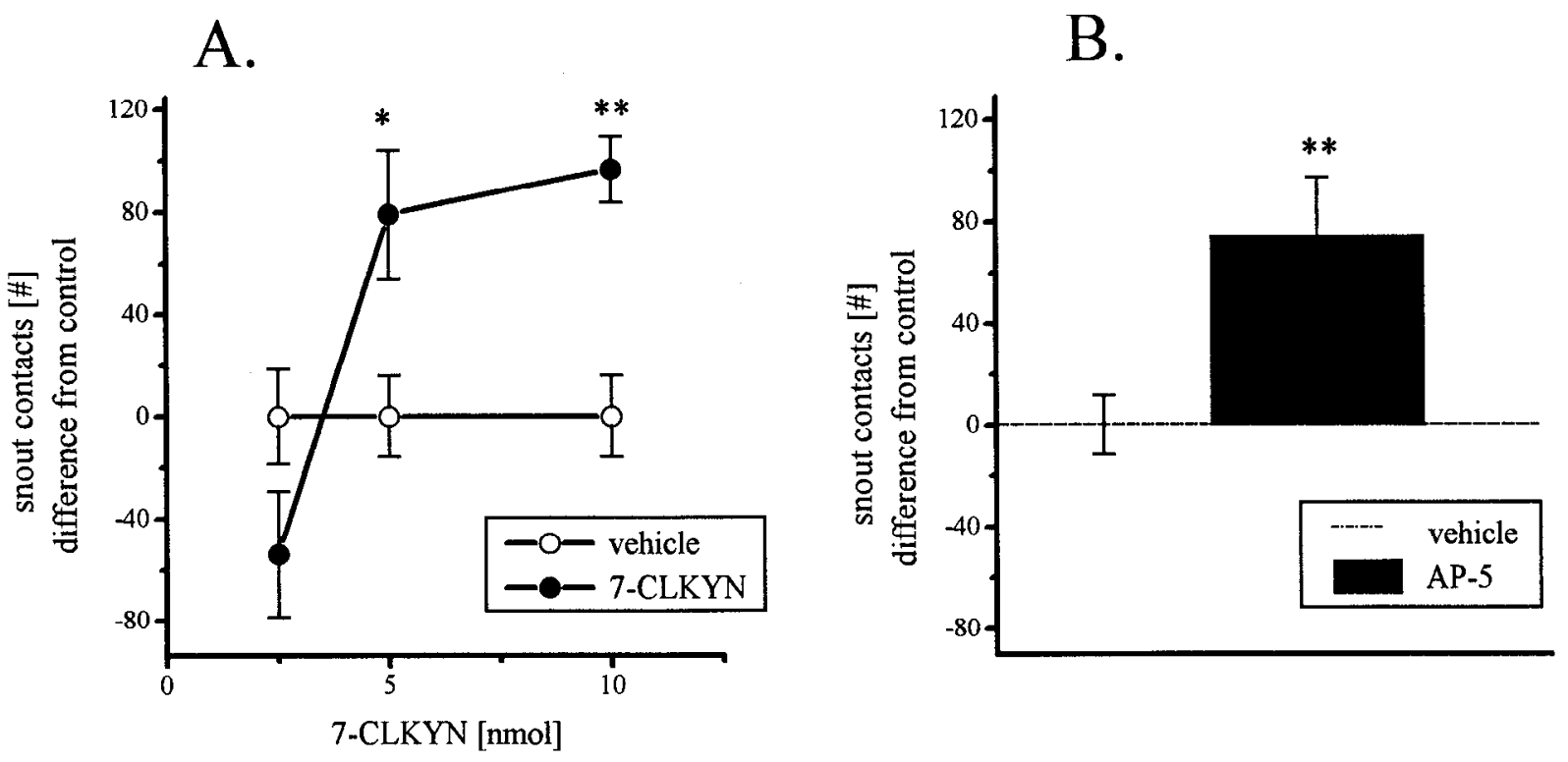

Figure 3. A, Effects of 2.5-10 nmol of 7-chlorokynurenate (7-CLKYN) on stereotypical snout contacts in the anterodorsal striatum. For clarity, data are presented as differences from control mean \pm SEM. Means of raw data are: vehicle/7-CLKYN (2.5 nmol) $250.3 \pm 18.6 / 196.4 \pm 24.7$ snout contacts per $5 \min (n=10 / 10)$; vehicle/7-CLKYN $(5 \mathrm{nmol}) 168.9 \pm 15.9 / 247.8 \pm 25.2$ snout contacts per $5 \mathrm{~min}(n=10 / 10)$; vehicle/7-CLKYN $(10 \mathrm{nmol}) 136.8 \pm$ $15.9 / 233.3 \pm 12.9$ snout contacts per 5 min $(n=12 / 14)$. For statistical evaluation, raw data were analyzed by one-way ANOVA followed by Tukey's $t$ test, ${ }^{*} p<0.05,{ }^{* *} p<0.01$ compared with vehicle-treated rats. $B$, Effects of $50 \mathrm{nmol}$ of AP-5 on stereotypical snout contacts in the anterodorsal striatum. Means of raw data are: vehicle/AP-5 $106.8 \pm 11.7 / 181.2 \pm 22.8$ snout contacts per 5 min $(n=12 / 13)$. For statistical evaluation, raw data were analyzed by $t$ test, ${ }^{* *} p<0.01$ compared with vehicle-treated rats.

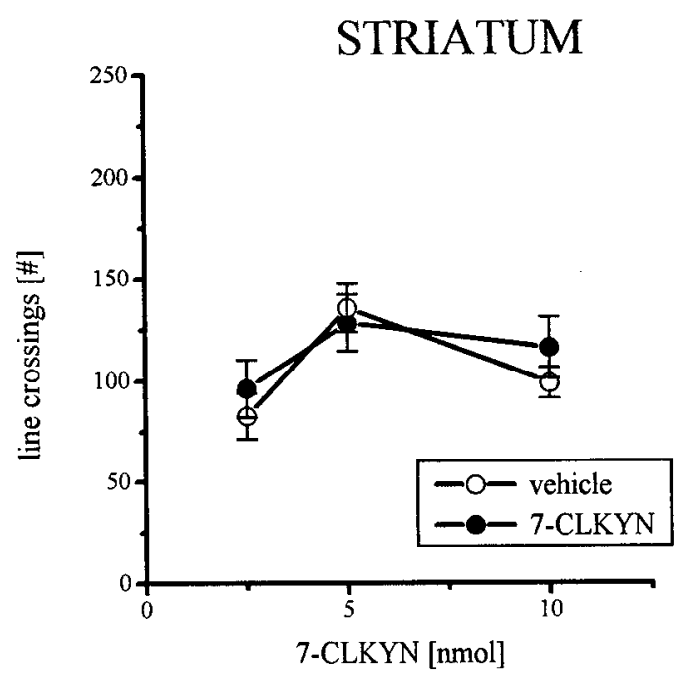

Figure 4. Effects of $2.5-10 \mathrm{nmol}$ of 7-chlorokynurenate $(7-C L K Y N)$ on locomotor behavior (number of line crossings) in the anterodorsal striatum. Mean \pm SEM presented. Vehicle/7-CLKYN $(2.5 \mathrm{nmol}) n=10 / 11$; vehicle/7-CLKYN $(5 \mathrm{nmol}) n=10 / 10$; vehicle 7 -CLKYN $(10 \mathrm{nmol}) n=$ 13/12. Data were analyzed by one-way ANOVA.

accumbens (Schmidt and Bury, 1988; Klockgether and Turski, 1993; Svensson et al., 1994), others found that NMD^ enhances motor activity or has no effect (Donzanti and Uretsky, 1984; Raffa et al., 1989; Imperato et al., 1990; Yoshida et al., 1991; Svensson et al., 1994). Different doses and a toxic mechanism of NMDA may explain these heterogeneous results. In this respect, it has been shown that high doses of NMDA enhance dopamine release in a TTX-insensitive manner and that the induced locomotion is accompanied by convulsions, whereas lower doses are ineffective in influencing these parameters (O'Neill et al., 1989; Imperato et al., 1990; Wedzony el al., 1991; Svensson et al., 1994). Glycine-site agonists are devoid of toxic actions but are also devoid of effects on sniffing behavior and spontaneous locomotion. However, they enhance the effects of noncompetitive NMDA receptor antagonists and reduce the effects of competitive NMDA receptor antagonists (Kretschmer et al., 1992). Thus, the glycine site of the NMDA receptor complex meets its regulatory and modulatory function and becomes important if transmitter balances are changed.

The effects of the glycine-site antagonist 7-chlorokynurenate in the striatum and nucleus accumbens correspond to earlier findings showing that intraventricular or systemic injections of glycinesite antagonists enhance stereotypical snout contacts, have no effect on locomotion, and reduce dopamine D2 receptor-but not D1 receptor-mediated catalepsy (Koek and Colpaert, 1990; Hutson et al., 1991; Bristow et al., 1993; Kretschmer, 1994; Kretschmer et al., 1994, 1995). Furthermore, the finding that the glycine-site antagonist more effectively induces stereotypical snout contacts when injected in the anterodorsal striatum than in the nucleus accumbens supports the notion that these two structures may contribute differentially to motor behavior. Howcver, the effects are only moderate.

The suggestion of the functional dichotomy has been derived from earlier behavioral findings showing that activation of the dopaminergic system and blockade of NMDA receptors also have a greater influence on sniffing behavior in the striatum and a greater influence on locomotor behavior in the nucleus accumbens (Creese and Iversen, 1975; Kelly et al., 1975; Staton and Solomon, 1984; McCullough and Salamone, 1992; Schmidt et al., 


\section{STRIATUM}

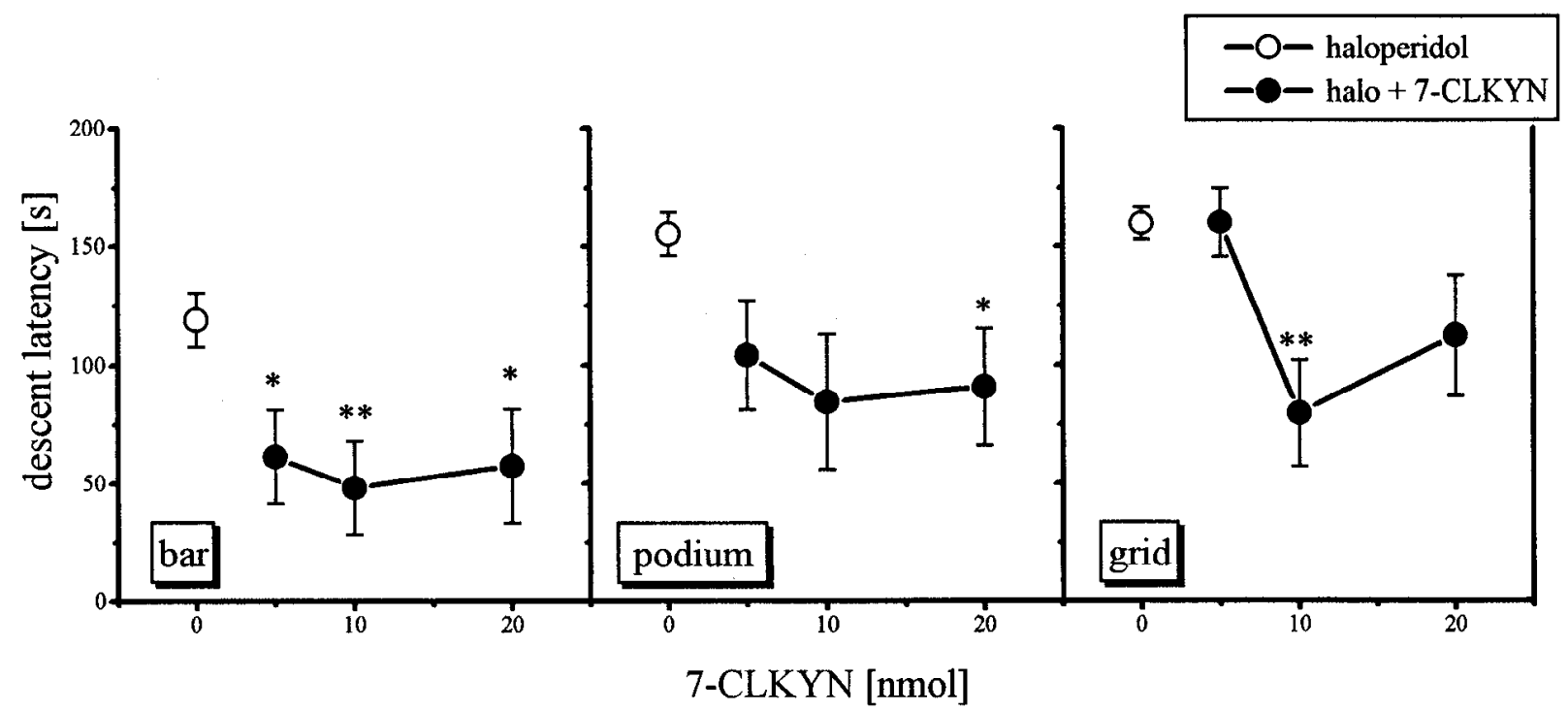

Figure 5. Effects of 5-20 nmol of 7-chlorokynurenate (7-CLKYN) on haloperidol (halo) induced catalepsy in the anterodorsal striatum. Time until active movement on one paw was measured (descent latency) at horizontal bar (bar), podium, and vertical grid (grid). Mean \pm SEM are presented. Halo (0.5 $\mathrm{mg} / \mathrm{kg}$, i.p.) $n=28$; halo +7 -CLKYN $(5 \mathrm{mmol}) n=11$; halo +7 -CLKYN $(10 \mathrm{nmol}) n=10$; halo +7 -CLKYN $(20$ nmol $) n=9$. Dala were allalyzed by Kruskal-Wallis test followed by Mann-Whitney $U$ test. ${ }^{*} p<0.05,{ }^{* *} p<0.01$ compared with haloperidol-treated rats.

\section{STRIATUM}

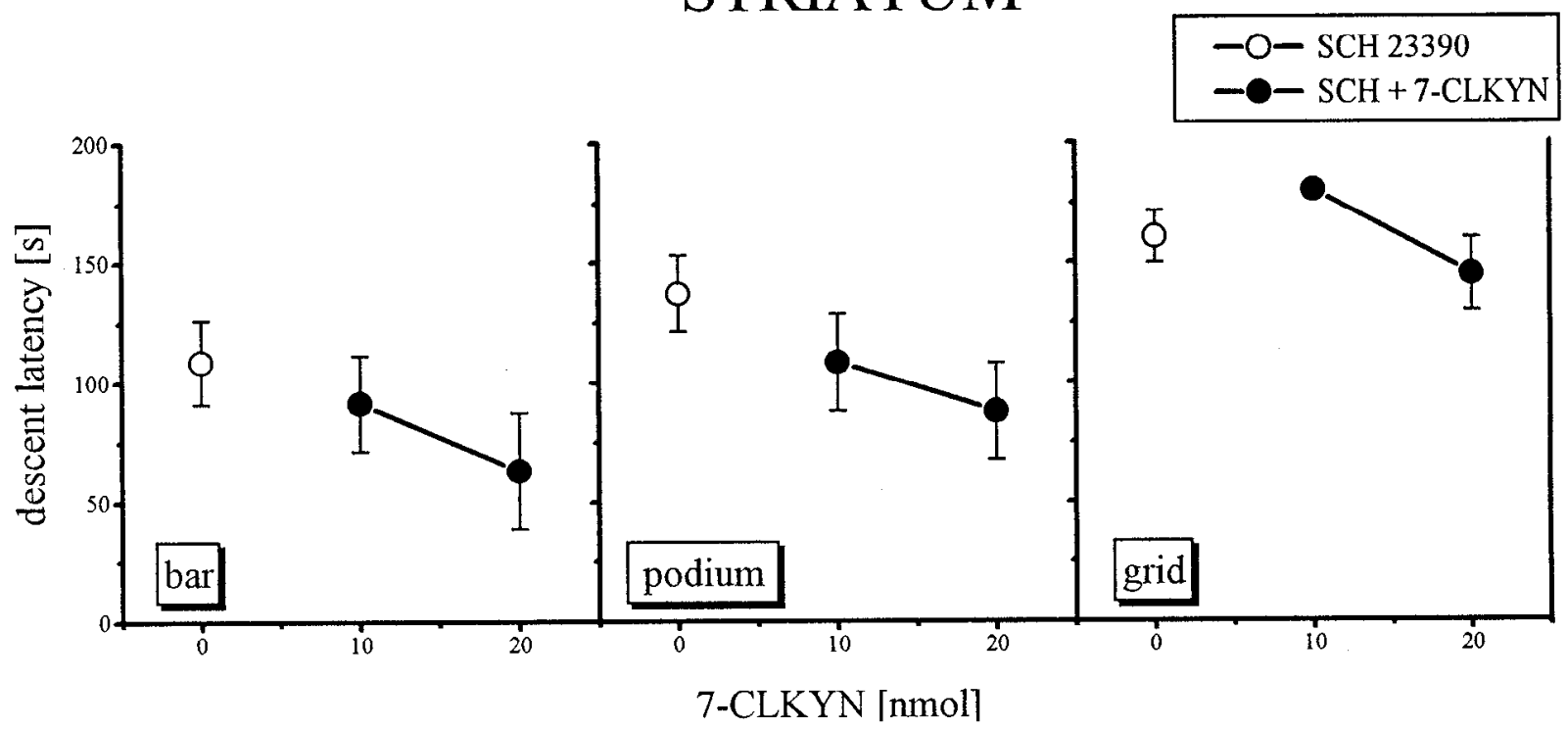

Figure 6. Effects of 10 and $20 \mathrm{nmol}$ of 7-chlorokynurenate (7-CLKYN) on SCH $23390(S C H)$ induced catalepsy in the anterodorsal striatum. Time until active movement on one paw was measured (descent latency) at horizontal har (har), podium, and vertical grid (grid). Mean \pm SEM are presented. SCH $(0.5 \mathrm{mg} / \mathrm{kg}$, i.p. $) n=17$; SCH +7 -CLKYN $(10 \mathrm{nmol}) n=9 ; \mathrm{SCH}+7$-CLKYN $(20 \mathrm{nmol}) n=6$. Data were analyzed by Kruskal-Wallis test followed by Mann-Whitney $U$ test.

1992). In addition, anatomical findings may support the idea, indicating that the termination areas of the sensorimotor-related projections from the striatum and the limbicmotor-related projections from the nucleus accumbens terminate in two distinct parts of substantia nigra pars reticulata (SNr) and thalamus: for the striatum, in ventromedial and ventrolateral parts, and for the nucleus accumbens, in dorsomedial parts of the respective structures (Ricardo, 1980; Graybiel, 1984; Berendse et al., 1992; Haber et al., 1993; Lynd-Balta and Haber, 1994). Assuming that this functional dichotomy is correct [which is not completely sup- ported by the present results and has been discussed controversially in the past (LeMoal and Simon, 1991)], it is interesting that stereotypical snout contacts are also obtained by blockade of accumbal glycine sites.

A tentative explanation for this effect may be that glycine-site antagonists may enhance stereotypical snout contacts via a direct link of the sensorimotor-related and the limbicmotor-related loop. This link is given by afferents from the nucleus accumbens reaching not only the SNr and the ventral pallidum (VP), but also the substantia nigra pars compacta (Pennartz et al., 1994). They 
Table 1. Behavioral effects of NMDA/glycine receptor agonists on stereotypical snout contacts and locomotor behavior after intrastriatal injection

\begin{tabular}{|c|c|c|c|c|c|}
\hline Substance & Dose & $n$ & $\begin{array}{l}\text { Snout contacts } \\
\text { per } 5 \text { min }\end{array}$ & $n$ & $\begin{array}{l}\text { Line crossings } \\
\text { per } 5 \mathrm{~min}\end{array}$ \\
\hline Vehicle & $0.6 \mu \mathrm{l}$ & 10 & $240.2 \pm 11.2$ & 12 & $105.7 \pm 11.2$ \\
\hline D-Serine & $1.0 \mu \mathrm{mol}$ & 13 & $243.8 \pm 18.7$ & 12 & $116.8 \pm 14.5$ \\
\hline Vehicle & $0.6 \mu \mathrm{l}$ & 12 & $210.1 \pm 16.9$ & 14 & $114.8 \pm 5.1$ \\
\hline D-Serine & $1.5 \mu \mathrm{mol}$ & 11 & $167.5 \pm 13.3^{\mathrm{ns}}$ & 13 & $127.6 \pm 10.9$ \\
\hline Vehicle & $0.5 \mu \mathrm{l}$ & 12 & $126.0 \pm 11.0$ & 1 & 1 \\
\hline NMDA & $6.8 \mathrm{nmol}$ & 10 & $88.8 \pm 10.3^{*}$ & / & / \\
\hline
\end{tabular}

For statistical evaluation data were analyzed by a one-way ANOVA (D-serine) and by $t$-test (NMDA). NS, Not significant; *a significant difference $p \leq 0.05$.

\section{N. ACCUMBENS}

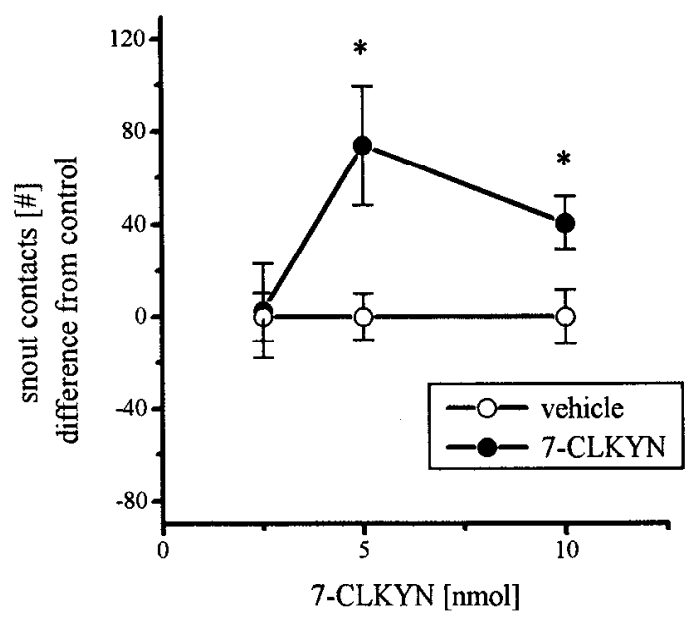

Figure 7. Effects of 2.5-10 nmol of 7-chlorokynurenate (7-CLKYN) on stereotypical snout contacts in the nucleus accumbens. For clarity, data are presented as differences from control mean \pm SEM. Means of raw data are: vehicle/7-CLKYN (2.5 nmol) $156.2 \pm 10.4 / 158.7 \pm 20.6$ snout contacts per $5 \min (n=10 / 10)$; vehicle 7 -CLKYN $(5 \mathrm{nmol}) 196.1 \pm 9.9 / 270 \pm 25.5$ snout contacts per $5 \mathrm{~min}(n=10 / 11)$; vehicle/7-CLKYN $(10 \mathrm{nmol}) 137.7 \pm$ $11.7 / 178.3 \pm 11.3$ snout contacts per $5 \min (n=14 / 16)$. For statistical evaluation, raw data were analyzed by one-way ANOVA followed by Tukey's $t$ test, ${ }^{*} p<0.05$ compared with vehicle-treated rats.

are GABAergic and terminate directly on the dopaminergic nigrostriatal neurons (Somogyi et al., 1981), and may directly modulate the function of the sensorimotor-related loop. Nevertheless, a diffusion process of the glycine-site antagonist into the striatum cannot been excluded.

An alternative explanation for the enhanced stereotypical snout contacts after injection of 7-chlorokynurenate into the nucleus accumbens may be that a strict anatomical-functional dichotomy is not given for the behavioral effects of the glycine-site antagonist, although a different sensitivity of the glycine sites in the striatum and the nucleus accumbens exists.

The finding that the glycine-site antagonist 7-chlorokynurenate has no effect on spontaneous locomotion when injected into the nucleus accumbens or striatum was exciting because the present study shows that NMDA receptor heterogeneity can also have consequences on motor behavior.

The reason for this heterogeneity is unknown, but could be attributable to the heteromeric nature of the NMDA receptor complex: in vitro studies showed that an active NMDA receptor complex consists of two receptor subunits, an NMDAR1 subunit and one of four NMDAR2 (NMDAR2a-NMDAR2d) subunits. The four different NMDAR2 subunits have different affinities for glycine or glycine-site ligands. Thus, the pharmacological properties of the active NMDA receptor complex vary depending on the subunit assembly (Bigge, 1993; Seeburg, 1993). This has been supported by binding studies, which suggest that in the striatum and the cortex, the NMDA receptor complex has a high affinity to glycine-site antagonists (Sakurai et al., 1993). Therefore, glycine sites that have a low affinity for antagonists might be responsible for the inability of glycine-site antagonists to induce locomotion in the nucleus accumbens.

Catalepsy induced by dopamine D2 and D1 receptor antagonists is mediated by the striatum (Ellenbroek et al., 1985; Ossowska et al., 1990; Yoshida et al., 1991, 1994). Systemically and locally applied NMDA receptor antagonists and ablation of the frontal cortex reduce the cataleptic symptoms induced by dopamine D2 receptor antagonists because of the opposite action of dopamine at the D2 receptor and glutamate at the NMDA receptor in the striatum (Schmidt and Bubser, 1989; Yoshida et al., 1991, 1994; Kretschmer et al., 1992). Glycine-site antagonists also reduce the cataleptogenic actions of the dopamine $\mathrm{D} 2$ receptor antagonist haloperidol after systemic or intracerebroventricular (ICV) and, as shown here, local application into the striatum, as it was proposed (Kretschmer, 1994; Kretschmer et al., 1994). However, it is amazing that systemically given NMDA receptor antagonists reduce dopamine D1-mediated catalepsy (Schmidt et al., 1991; Verma and Kulkarni, 1992), whereas intrastriatally (see above) and systemically or ICV-administered glycine-site antagonists fail to do so (Kretschmer, 1994; Kretschmer et al., 1994).

One interpretation of the basis of functional anatomy may be that the striatum projects via two efferent pathways to lower BG nuclei [SNr and entopeduncular nucleus (EP)]: (1) via a direct striatonigral pathway; and (2) via an indirect pathway, passing the globus pallidus and the subthalamic nucleus. Dopamine D1 receptors are located mainly on the striatonigral pathway and excite the GABAergic efferents, whereas dopamine D2 receptors are located mainly on the indirect pathway and inhibit the GABAergic pathway (Gerfen et al., 1990). A strict separation of dopamine D1 and D2 receptors has often been postulated, but an overlap of $10-50 \%$ has been found after mRNA or retrograde labeling, after c-fos expression, or after selective lesion of striatopallidal neurons (Gerfen et al., 1990; Harrison et al., 1992; Robertson et al., 1992; Surmeier et al., 1992). Given that dopamine D1 and D2 receptors are distributed differently on the striatal efferents, the blockade of striatal dopamine D2 and D1 receptors enhances the activity of the $\mathrm{SNr}$ and EP. NMDA receptor antagonists can reduce the effects of dopamine D2 receptor antagonists because NMDA receptors and dopamine $\mathrm{D} 2$ receptors have opposite effects on the indirect pathway. But how can an NMDA receptor antagonist antagonize the effects of dopamine D1 receptor antagonists? (1) The NMDA receptor antagonists may be able to reduce the 


\section{N. ACCUMBENS}
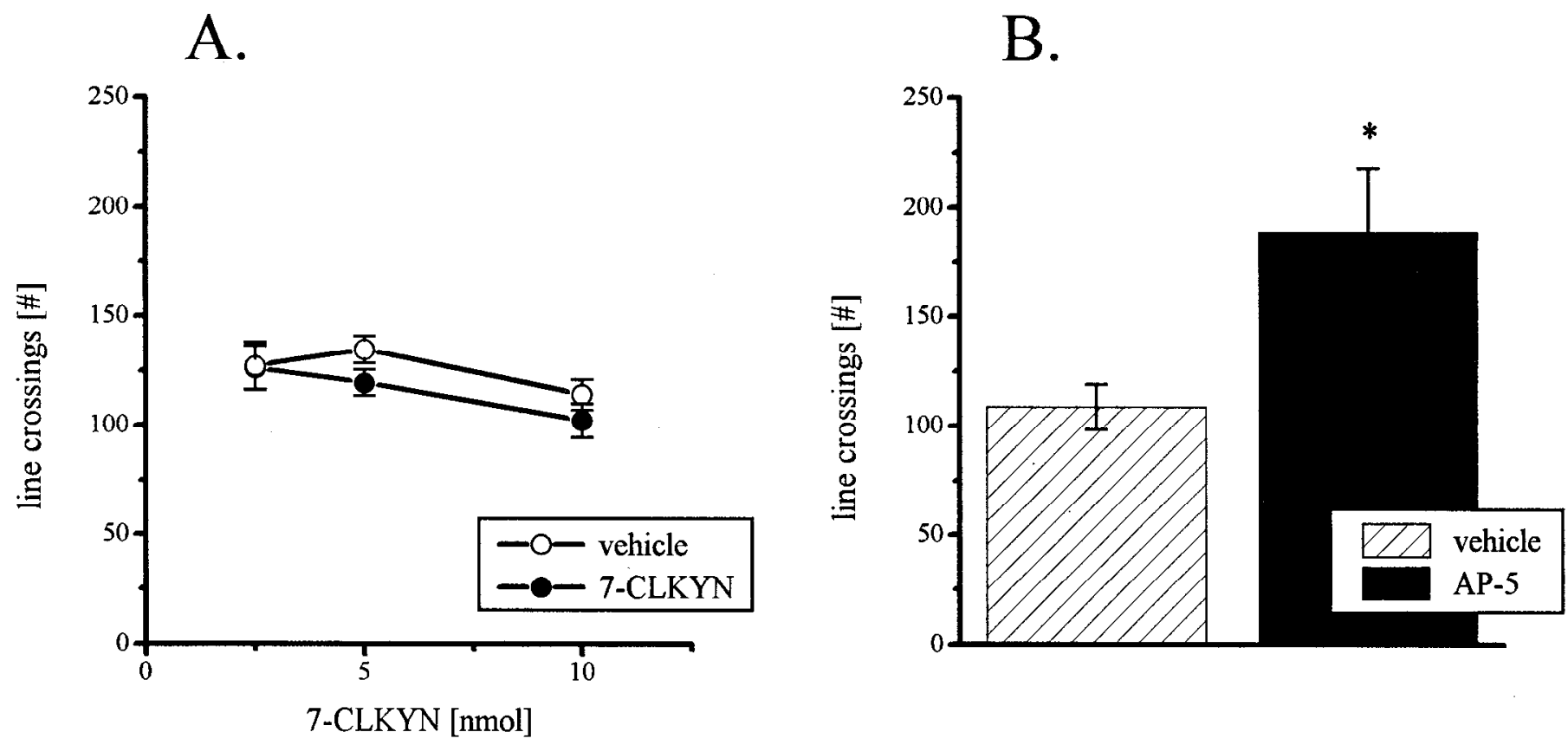

Figure 8. A, Effects of 2.5-10 nmol of 7-chlorokynurenate (7-CLKYN) on locomotor behavior (number of line crossings) in the nucleus accumbens. Mean \pm SEM are presented. Vehicle/7-CLKYN $(2.5 \mathrm{nmol}) n=8 / 10$; vehicle/7-CLKYN $(5 \mathrm{nmol}) n=11 / 10$; vehicle/7-CLK YN $(10 \mathrm{nmol}) n=10 / 11$. Data were analyzed by one-way ANOVA. $B$, Effects of $50 \mathrm{nmol}$ of AP-5 on locomotor behavior (number of line crossings) in the nucleus accumbens. Mean \pm SEM are presented. Vehicle/AP-5 $n=7 / 8$. Data were analyzed by $t$ test, ${ }^{*} p<0.05$ compared with vehicle-treated rats.

\begin{tabular}{|c|c|c|c|c|c|}
\hline Substance & Dose & $n$ & $\begin{array}{l}\text { Snout contacts } \\
\text { per } 5 \text { min }\end{array}$ & $n$ & $\begin{array}{l}\text { Line crossings } \\
\text { per } 5 \text { min }\end{array}$ \\
\hline Vehicle & $0.5 \mu \mathrm{l}$ & 10 & $106.2 \pm 15.7$ & 10 & $82.2 \pm 14.5$ \\
\hline 7-Chlorokynurenate & $10.0 \mathrm{nmol}$ & 10 & $146.0 \pm 13.9$ & 10 & $50.5 \pm 11.8$ \\
\hline
\end{tabular}

For statistical evaluation, data were analyzed by $t$-test.

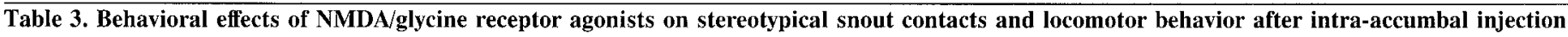

\begin{tabular}{|c|c|c|c|c|c|}
\hline Substance & Dose & $n$ & $\begin{array}{l}\text { Snout contacts } \\
\text { per } 5 \mathrm{~min}\end{array}$ & $n$ & $\begin{array}{l}\text { Line crossings } \\
\text { per } 5 \mathrm{~min}\end{array}$ \\
\hline Vehicle & $0.6 \mu \mathrm{l}$ & 10 & $178.7 \pm 23.3$ & 18 & $121.3 \pm 6.8$ \\
\hline D-Serine & $1.0 \mu \mathrm{mrol}$ & 10 & $131.3 \perp 25.4^{\mathrm{ns}}$ & 10 & $101.1 \perp 10.3^{\mathrm{ns}}$ \\
\hline Vehicle & $0.6 \mu \mathrm{l}$ & 7 & $141.7 \pm 27.2$ & 9 & $133.4 \pm 5.5$ \\
\hline D-Serine & $1.5 \mu \mathrm{mol}$ & 7 & $205.6 \pm 25.2^{\mathrm{ns}}$ & 16 & $129.2 \pm 10.8$ \\
\hline Vehicle & $0.5 \mu \mathrm{l}$ & $/$ & 1 & 20 & $83.1 \pm 7.6$ \\
\hline NMDA & $6.8 \mathrm{nmol}$ & 1 & 1 & 19 & $82.5 \pm 10.5$ \\
\hline
\end{tabular}

For statistical evaluation, data were analyzed by a one-way ANOVA (D-serine) and by $t$-test (NMDA). NS, Not significant.

hyperactivity of the SNr and EP neurons via the indirect pathway by blocking the striatopallidal output. A glycine-site antagonist, acting as a functional NMDA receptor antagonist against dopamine D2 receptor mediated catalepsy, does not affect the cataleptic symptoms of a dopamine D1 receptor antagonist after intrastriatal application via this pathway. Thus, it seems unlikely that NMDA receptor antagonists have an important influence via the indirect pathway against D1 catalepsy. (2) Anatomical data show that NMDA receptors are located in the striatum as well as in lower BG (SNr and EP) (Albin et al., 1992). Lesioning the SNr or
EP with quinolinic acid antagonizes dopamine D2- and D1 receptor-mediated catalepsy (Zadow and Schmidt, 1994a,b). Therefore, it seems be more likely that NMDA receptor antagonists, but not glycine-site antagonists, reduce dopamine D1mediated catalepsy by blocking the SNr and EP neurons directly. It may be speculated that the NMDA receptor complex located in these structures also may have a low-affinity glycine site as it is proposed for accumbopallidal (nucleus accumens-VP) and accumbonigral (nucleus accumbens-SNr) efferents.

It can be concluded that, in contrast to what we expected, the 




Figure 9. Model of the glutamate/glycine control of motor behavior via the sensorimotor-related and the limbicmotor-related loop of the basal ganglia. $G P$, Globus pallidus; $S T N$, subthalamic nucleus; $S N r / E P$, substantia nigra pars reticulata/entopeduncular nucleus; $V P$, ventral pallidum.

coupling of the glycine site to the NMDA receptor complex shows regional differences in the BG. A modulatory function of glycine sites on behavior mediated by the striatonigral output pathway of the sensorimotor-related loop and by the accumbopallidal output pathway of the limbicmotor-related loop seems unlikely with respect to the results of the present study. In contrast, behavior mediated by the striatopallidal loop of the sensorimotor-related pathway can be modulated by the allosteric glycine site of the NMDA receptor complex (Fig. 9).

\section{REFERENCES}

Albin RL, Makowiec RL, Hollingsworth ZR, Dure IV LS, Penny JB, Young AB (1992) Excitatory amino acid binding sites in the basal ganglia of the rat: quantitative autoradiographic study. Neuroscience 46:35-48.

Alexander GE, Crutcher MD (1990) Functional architecture of basal ganglia circuits: neural substrates of parallel processing. Trends Neurosci $13: 266-271$

Alexander GE, DeLong MR, Strick PL (1986) Parallel organization of functionally segregated circuits linking basal ganglia and cortex. Annu Rev Neurosci 9:357-381.

Berendse HW, Groenewegen HJ, Lohman AM (1992) Compartmental distribution of ventral striatal neurons projecting to the mesencephalon in the rat. J Neurosci 12:2079-2103.

Bigge CF (1993) Structural requirements for the development of potent $N$-methyl-D-aspartic acid (NMDA) receptor antagonists. Biochem Pharmacol 45:1547-1561.

Bristow LJ, Hutson PH, Thorn L, Tricklebank MD (1993) The glycine/ NMDA receptor antagonist, R-(+)-HA-966, blocks activation of the mesolimbic dopamine system induced by phencyclidine and dizocilpine (MK-801) in rodents. Br J Pharmacol 108:1156-1163.

Calderon SF, Sanberg PR, Norman AB (1988) Quinolinic acid lesions of rat striatum abolish D1- and D2- dopamine receptor-mediated catalepsy. Brain Res 450:403-407.

Creese I, Iversen SD (1975) The pharmacological and anatomical substrates of amphetamine response in the rat. Brain Res 83:419-436.

Donzanti BA, Uretsky NJ (1984) Antagonism of the hypermotility response induced by excitatory amino acids in the rat nucleus accumbens. Naunyn-Schmiedebergs Arch Pharmacol 325:1-7.

Ellenbroek B, Schwarz M, Sontag K-H, Jaspers R, Cools A (1985) Muscular rigidity and delineation of a dopamine-specific neostriatal subregion: tonic EMG activity in rats. Brain Res 345:132-140.

Gerfen CR, Engber TM, Mahan LC, Sussel Z, Chase TN, Monsma FJ, Sibley DR (1990) D1 and D2 dopamine receptor-regulated gene expression of striatonigral and striatopallidal neurons. Science 250:1429-1432.

Graybiel AM (1984) Neurochemically specified subsystems in the basal ganglia. In: Functions of the basal ganglia, Ciba Foundation Symposium 107, pp 114-149. London: Pitman.

Haber SN, Lynd-Balta E, Mitchell SJ (1993) The organization of the descending ventral pallidal projections in the monkey. J Comp Neurol $329: 111-128$.
Harrison MB, Wiley RG, Wooten GF (1992) Changes in D2 but not D1 receptor binding in the striatum following a selective lesion of striatopallidal neurons. Brain Res 590:305-310.

Hauber W, Schmidt WJ (1993) Discrete quinolinic acid lesions of the lateral but not of the medial caudate-putamen reversed haloperidolinduced catalepsy in rats. J Neural Transm 94:103-114.

Hutson PH, Bristow LJ, Thorn L, Tricklebank MD (1991) R-(+)-HA966 , a glycine/NMDA receptor antagonist, selectively blocks the activation of the mesolimbic dopamine system by amphetamine. Br J Pharmacol 103:2037-2044.

Imperato A, Scrocco MG, Bacchi S, Angelucci L (1990) NMDA receptors and in vivo dopamine release in the nucleus accumbens and caudatus. Eur J Pharmacol 187:555-556.

Iversen SD, Wilkinson S, Simpson B (1971) Enhanced amphetamine responses after frontal cortex lesions in the rat. Eur $\mathbf{J}$ Pharmacol 13:387-390.

Kelley AE, Throne LC (1992) NMDA receptors mediate the behavioral effects of amphetamine infused into the nucleus accumbens. Brain Res Bull 29:247-254.

Kelly PH, Seviour PW, Iversen SD (1975) Amphetamine and apomorphine responses in the rat following 6-OHDA lesions of the nucleus accumbens septi and corpus striatum. Brain Res 94:507-522.

Klockgether T, Turski L (1993) Toward an understanding of the role of glutamate in experimental Parkinsonism: agonist-sensitive sites in the basal ganglia. Ann Neurol 34:585-593.

Koek W, Colpaert FC (1990) Selective blockade of $N$-methyl-D-aspartate (NMDA)-induced convulsions by NMDA antagonists and putative glycine antagonists: relationship with phencyclidine-like behavioral effects. J Pharmacol Exp Ther 252:349-357.

Kretschmer BD (1994) Felbamate, an anti-convulsive drug, has antiparkinsonian potential in rats. Neurosci Lett 179:115-118.

Kretschmer BD, Zadow B, Volz TL, Volz L, Schmidt WJ (1992) The contribution of the different binding sites of the $N$-methyl-D-aspartate (NMDA) receptor to the expression of behavior. J Neural Transm 87:23-35.

Kretschmer BD, Winterscheid B, Danysz W, Schmidt WJ (1994) Glycine site antagonists abolish dopamine D2 but not D1 receptor mediated catalepsy in rats. J Neural Transm 95:123-136.

Kretschmer BD, Bubser M, Schmidt WJ (1995) Behavioral and neurochemical actions of the strychnine-insensitive glycine receptor antagonist, 7-chlorokynurenate, in rats. Eur J Pharmacol 280:37-45.

LeMoal M, Simon H (1991) Mesocorticolimbic dopaminergic network: functional and regulatory roles. Physiol Rev 71:155-234.

Lynd-Balta E, Haber SN (1994) Primate striatonigral projections: a comparison of the sensorimotor-related striatum and the ventral striatum. J Comp Neurol 345:562-578.

McCullough LD, Salamone JD (1992) Increase in extracellular dopamine levels and locomotor activity after direct infusion of phencyclidine into the nucleus accumbens. Brain Res 577:1-9.

Meyer MM (1993) Effects of intraaccumbens dopamine agonist SK\&F38393 and antagonist SCH23390 on locomotor activities in rats. Pharmacol Biochem Behav 45:843-847.

O'Neill KA, Carelli RM, Jarvis MF, Liebman JM (1989) Hyperactivity induced by $N$-methyl-D-aspartate injections into nucleus accumbens: lack of evidence for mediation by dopaminergic neurons. Pharmacol Biochem Behav 34:739-745.

Ossowska K, Karcz M, Wardas J, Wolfarth S (1990) Striatal and nucleus accumbens D1/D2 dopamine receptors in neuroleptic catalepsy. Eur J Pharmacol 182:327-334.

Paxinos G, Watson C (1986) The rat brain in stereotaxic coordinates. Sydney: Academic.

Pellegrino LJ, Pellegrino AS, Cushman AJ (1986) A stereotaxic atlas of the rat brain. New York: Plenum.

Pennartz CMA, Groenewegen HJ, Lopes da Silva FH (1994) The nucleus accumbens as a complex of functionally distinct neuronal ensembles: an integration of behavioural, electrophysiological and anatomical data. Prog Neurobiol 42:719-761.

Pierce RC, Rebec GV (1993) Intraneostriatal administration of glutamate antagonists increases behavioral activation and decreases neostriatal ascorbate via nondopaminergic mechanisms. J Neurosci 13:4272-4280.

Raffa RB, Ortegon ME, Robisch DM, Martin GE (1989) In vivo demonstration of the enhancement of MK- 801 by L-glutamate. Life Sci 44:1593-1599.

Ricardo JA (1980) Efferent connections of the subthalamic region in the rat. I. The subthalamic nucleus of luys. Brain Res 202:257-271. 
Robertson GS, Vincent SR, Fibiger HC. (1992) D1 and D? dopamine receptors differentially regulate c-fos expression in striatonigral and striatopallidal neurons. Neuroscience 49:285-296.

Sakurai SY, Penny JB, Young AB (1993) Regionally distinct $N$-methylD-aspartate receptors distinguished by quantitative autoradiography of $\left[{ }^{3} \mathrm{H}\right] \mathrm{MK}-801$ binding in rat brain. J Neurochem 60:1344-1353.

Scatton B, Worms P, Lloyd KG, Bartholini G (1982) Cortical modulation of striatal function. Brain Res 232:331-343

Schmidt WJ (1986) Intrastriatal injection of DL-2-amino-5-phosphonovaleric acid (AP-5) induces sniffing stereotypy that is antagonized by haloperidol and clozapine. Psychopharmacology 90:123-130.

Schmidt WJ, Bubser M (1989) Anticataleptic effects of the $N$-methyl-Daspartate antagonist $\mathrm{MK}-801$ in rats. Pharmacol Biochem Behav 32:621-623.

Schmidt WJ, Bury D (1988) Behavioural effects of $N$-methyl-D-aspartate in the anterodorsal striatum in the rat. Life Sci 43:545-549.

Schmidt WJ, Zadow B, Kretschmer BD, Hauber W (1991) Anticataleptic potcncics of glutamatc-antagonists. Amino Acids 1:225-237.

Schmidt WJ, Bury D, Geltz U (1992) Dopamine-glutamate interactions in the basal ganglia. In: Dopamin '92-from neurobiology to neuropathology, $\mathrm{p} 90$.

Seeburg PH (1993) The Trends Neurosci/TiPS lecture-the molecular biology of mammalian glutamate receptor channels. Trends Neurosci 16:359-365.

Somogyi P, Bolam JP, Totterdell S, Smith AD (1981) Monosynaptic input from the nucleus accumbens-ventral striatum region to retrogradely labelled nigrostriatal neurones. Brain Res 217:245-263.

Staton DM, Solomon PR (1984) Microinjection of D-amphetamine into the nucleus accumbens and caudatus putamen differentially affect stereotypy and locomotion in the rat. Physiol Psychol 12:159-162.

Surmeier DJ, Eberwine J, Wilson CJ, Cao A, Stefani A, Kitai ST (1992) Dopamine receptor subtypes colocalize in rat striatonigral ncurons. Proc Natl Acad Sci USA 89:10178-10182.
Svensson I, 7hang I, Johannessen K, Fngel JA (1994) Effect of local infusion of glutamate analogue into the nucleus accumbens of rats: an electrochemical and behavioral study. Brain Res 643:155-161.

Swerdlow NR, Koob GF (1987) Lesions of the dorsomedial nucleus of the thalamus, medial prefrontal cortex and pedunculopontine nucleus: effects on locomotor activity mediated by nucleus accumbens-ventral pallidal circuitry. Brain Res 412:233-243.

Verma A, Kulkarni SK (1992) D1/D2 dopamine and $N$-methyl-Daspartate (NMDA) receptor participation in experimental catalepsy in rats. Psychopharmacology 109:477-483.

Wedzony K, Golembiowska K, Maj J (1991) A search for the effects of NMDA on the release of dopamine from the rat nucleus caudatus. In: Monitoring molecules in neuroscience (Rollema $\mathrm{H}$, Westerink BHC, Drijhout WJ, eds), pp 321-324. Groningen: University Centre for Pharmacy.

Weissenborn R, Winn P (1992) Regulatory behaviour, exploration and locomotion following NMDA or 6-OHDA lesions in the rat nucleus accumbens. Behav Brain Res 51:127-137.

Wroblewski JT, Danysz W (1989) Modulation of glutamate receptormolecular mechanism and functional implications. Annu Rev Pharmacol Toxicol 29:441-474.

Yoshida Y, Ono T, Kizú A, Fukushima R, Miyagishi T (1991) Striatal $N$-methyl-D-aspartate receptors in haloperidol-induced catalepsy. Eur J Pharmacol 203:173-180.

Yoshida Y, Ono T, Kawano K, Miyagishi T (1994) Distinct sites of dopaminergic and glutamatergic regulation of haloperidol-induced catalepsy within the rat caudate-putamen. Brain Res 639:139-148.

Zadow B, Schmidt WJ (1994a) Lesions of the entopeduncular nucleus and the subthalamic nucleus reduce dopamine antagonist-induced catalepsy in rat. Behav Brain Res 62:71-79.

Zadow B, Schmidt WJ (1994b) Role of the basal ganglia output nuclei in the mediation of catalepsy revealed by lesion studies with quinolinic acid in the rat. Behav Pharmacol 5:116. 